\title{
Estimating Self and Spouse Intelligence among Jordanians
}

\author{
Firas Al-Hamouri, * Adnan Atoum, Mohammad Melhem, \& Hamzeh Rababa \\ Yarmouk University, Jordan \\ AlBalqaa University, Jordan Yarmouk University, Jordan
}

Received: 29/6/2016 Accepted:3/8/2016

\begin{abstract}
The current study aimed at exploring self and spouse estimates of general and multiple intelligences among a sample of married Jordanian Students. Two-hundred and ten participants, recruited from Yarmouk and Al-Balqaa Universities, Jordan, completed a brief questionnaire based on those used in previous research which included an estimation of general IQ and each of the multiple intelligence sub-types. Results of the study partially replicated the results from other multiple intelligence self-estimate studies showing sex differences on general and logical intelligences, and confirmed previous research results that estimated verbal (linguistic) intelligence followed by numerical (logical) intelligence are the best significant predictors of estimated general intelligence. These results were discussed in terms of sex and cultural differences and some recommendations were made.
\end{abstract}

Keywords: Estimated-intelligence, multiple intelligences, sex differences, cross-cultural studies.

$$
\begin{aligned}
& \text { تقدير ذكاء الفرد و ثريك الحياة لدى الأردثيين }
\end{aligned}
$$

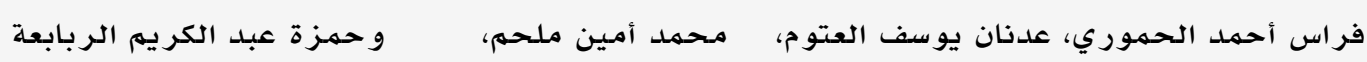

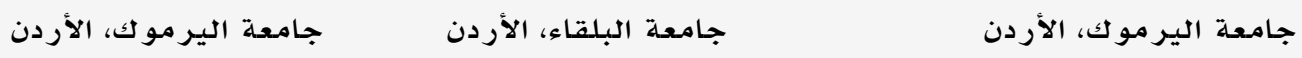

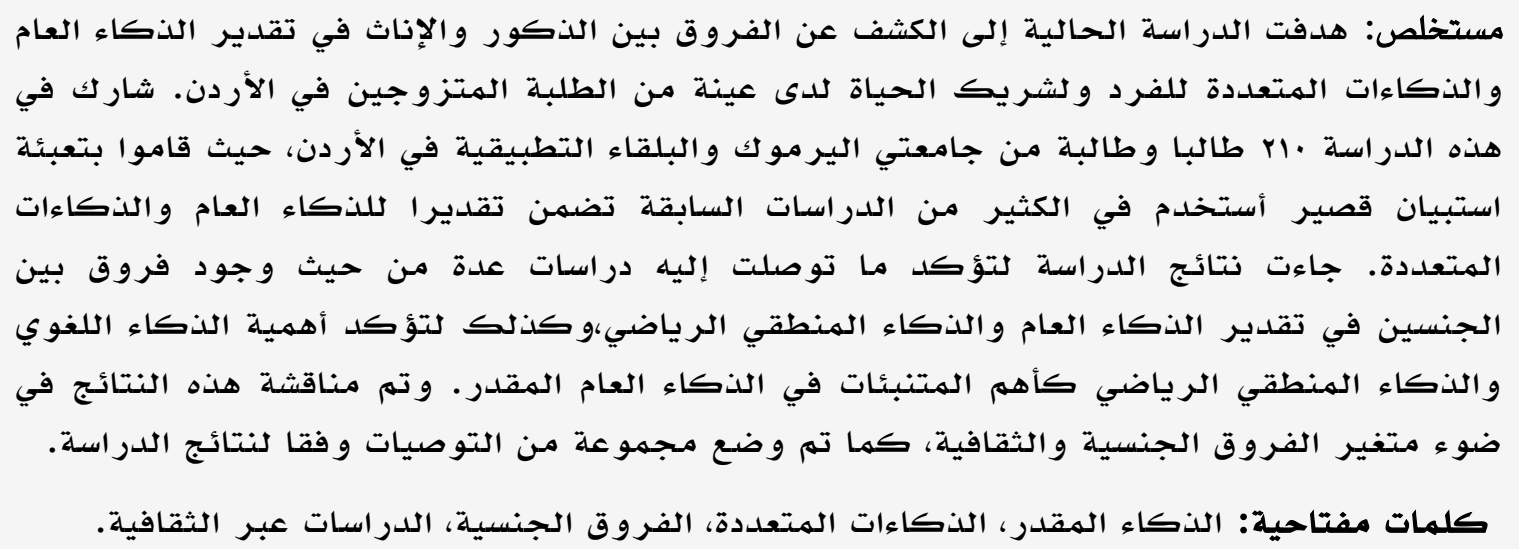


The concept and measurement of intelligence has been a debatable issue for several decades (Eysenck, 1998). However, psychologists in general still refer to human intelligence as a mental quality that contains abilities to learn from our own experiences, adapt to new environmental encounters, and solve problems over the course of human life. Several concerns have been discussed as to the stability and measurement of general IQ which led Howard Gardner to the idea of multiple intelligences. The new theory considered as a revolution against the stability perspective of general intelligence (Marlowe \& Canestrari, 2006).

Gardner (1999) identified seven intelligences in a comprehensive way that show the importance of individuality since he thought that individuals have different types of strengths and weaknesses in their abilities. Multiple intelligences as suggested by Gardner (1983, 2000) comprise three basic components. One that dealt with the human competence and implies problem solving skills and the second component dealt with the ability to achieve effective products or valued by the culture or society, and the third component dealt with the ability to reach creative solutions and acquiring new knowledge.

Intelligence in general as measured by IQ or intelligence abilities as proposed by Gardner have played a major role in evaluating individuals for several purposes such as achievement, friendship, success, and social relations. Therefore, judgment or estimation of intelligence remains a factor that plays a major role in psychology. Teachers' perception of their students' abilities have a direct influence on how they deal with them and even determine their grades (Gardner, 2006).

In real life situations, we often make judgments and estimations about our own intelligence and others around us such as students, spouses, children, parents, and associates. Believing that someone is intelligent is not a matter of guessing their IQ scores or mental abilities since these judgments do not necessarily correlate to specific measurements (Chamorro, 2016). Eysenck and Evans (1996) stated that psychologists have paid a lot of attention how to direct parents and teachers into making accurate estimates about kids' intelligence through means of signs and signals from our daily lives such as emotional maturity, the ability to learn and think critically and performance of certain tasks.

Furnham (2001) examined the importance of beliefs about self and others estimates of intelligence. He indicated that public beliefs and opinions about intelligence are important for social and academic interaction and adjustment, and estimating intelligence can affect our expectations about ourselves and others' which in return will affect our behavior or performance. Beyer (1999) also indicated that beliefs about intelligence can influence our activities and expectations. If individuals judged themselves as less intelligent than others, they may conform to this judgment on their behaviors. And if individuals made judgments that they are intellectually superior to others, it may lead to arrogance and complacency.

Furnham, Wytykowska and Petrides (2005) indicated that many studies have examined individual differences in estimating general intelligence or intelligence abilities for themselves or others. Gender differences in estimating intelligence in general have revealed a tendency that females provided lower selfestimates than males (Furnham, Fong, \& Martin, 1999; Furnham \& Gasson, 1998; Rammstedt \& Rammsayer, 2002). Furnham (2001) in a review study of 20 previous research articles reached the same conclusion that support consistent gender differences indicating that males were rating themselves higher than females.

In an early study, Bailey \& Mettetal (1977) tested the differences in estimating intelligence among married partners. The results showed differences in their perception of estimating intelligence where both husbands and wives were in favor of their own gender.

In a later study, Furnham and Ward (2001) examined sex differences in Gardner's abilities to predict estimation of general intelligence. Results showed that males believed that they were more intelligent than females in mathematical, spatial, and existential intelligence.

Similarly, Furnham, \& Chamorro-Premuzic (2005) found that the Argentinean data showed that men gave higher overall estimates than women, as well as higher estimates on mathematical and spatial intelligence. Also, Swami, Furnham, \& Kannan (2006) found that male Malaysians rated themselves higher than 
women on estimating overall intelligence and verbal, logical, and spatial intelligence. Also, the study found that subjects believed that verbal and logical (mathematics) were the best predictors of overall intelligence.

Furnham, Arteche, Chamorro-Premuzic, Keser \& Swami (2009) examined cross-cultural differences in beliefs about intelligence and self and other-estimated intelligence in Britain and Turkey. Primary results showed that both British and Turkish participants did not believe in sex differences in intelligence and believed in race differences since intelligence was inherited. However, data revealed that British male participants rated their overall, verbal, logical, spatial, creative and practical intelligence higher than females, while Turks rated their musical, body-kinesthetic, interpersonal and intrapersonal intelligence as well as existential, naturalistic, emotional, creative, and practical intelligence higher than the British.

Results from different cultures are showing different results. Furnham and Akande (2004) explored gender differences in estimating multiple intelligence among African parents. Mothers gave higher self-estimates of multiple intelligence than fathers.

The previous findings suggest a tendency toward gender differences in estimating intelligence and multiple intelligences in favor of males in most cultures. So the results may be affected by culture, age, and relationships between participants. These findings remain important because they have consequences on both females and males behaviors toward each other's and can have a self-fulfilling effect on both males and females relations and expectations across cultures (Furnham et al., 2005).

\section{Problem Statement}

Previous studies intended to study self and others' (father, mother, grandparents, and sons) estimates of intelligence and gender differences in these. Nevertheless, none of these studies tried to investigate differences between married people, although some of these studies included limited samples of married people (e.g., Furnham \& Ward, 2001; Furnham et al., 2005). This is the first study that pretends studying self and spouse estimated general and multiple intelligences in a sample of Jordanian married students. Based on the existing literature, the following hypotheses were formulated:
H1: Males will give statistically higher selfestimates than females on general and multiple intelligences.

H2: Males will give statistically higher spouseestimates than females on general and multiple intelligences.

H3: Male participants will rate themselves statistically higher than their spouses on general and multiple intelligences.

H4: Female participants will rate themselves statistically higher than their spouses on general and multiple intelligences.

H5: Multiple intelligences will be statistically significant predictors of general self and spouse intelligence both for male and female participants.

\section{Method}

\section{Participants}

Two-hundred and ten participants took part in this study. These were 45 male students and their wives, and 60 female students and their husbands. Students were recruited from Yarmouk and Al-Balgaa Universities in Irbid, Jordan. The average age of males was 32.88 years (SD 8.48), and of females was 26.58 years (SD 7.84).

\section{Materials and procedure}

Participants completed a brief questionnaire based on those used in previous research which included definitions of general IQ and each of the multiple intelligence sub-types. They were defined for participants as follows: 1. Verbal or linguistic intelligence (the ability to use words). 2. Logical or mathematical intelligence (the ability to reason logically, solve number problems). 3. Spatial intelligence (the ability to find your way around the environment, and form mental images). 4. Musical intelligence (the ability to perceive and create pitch and rhythm patterns). 5. Body-kinetic intelligence (the ability to carry out motor movement, e.g. being a surgeon or a dancer). 6. Interpersonal intelligence (the ability to understand other people). 7. Intrapersonal intelligence (the ability to understand yourself and develop a sense of your own identity). 8. Naturalistic intelligence (the ability to make distinctions in the natural world; and to use this ability productively in activities such as hunting, farming, and biological science). These 
definitions have been used in previous studies (Furnham, 2001).

The participants were also provided with a picture of a normal distribution of typical possible response scores, along with a label, description, and the prevalence in a normal population distribution. These were standard deviations: -3 (55) (mild retardation), -2 (70) (borderline retardation), -1 (85) (low average), 0 (100) (average), p1 (115) (high average), p2 (130) (superior) and p3 (145) (gifted). They were encouraged to place a number between 55 and 145 for all estimates. A response matrix was presented for completion by the participant.

The questionnaire of this study has been used in more than 30 studies done in 20 different countries and appears to be easily understood by a wide variety of people (Furnham \& Fukumoto, 2008). For the present study, the questionnaire was presented to five psychologists and they stated that the questionnaire was valid for this purpose. Also, Cronbach's Alpha was obtained on the sample data for self estimated general and multiple intelligences 0.80 with corrected item-total correlation values between 0.35 and 0.59 , and 0.82 for spouse estimated intelligences with corrected item-total correlation values between 0.37 and 0.61 , indicating a good reliability status.

\section{Results}

\section{Gender differences}

In order to explore the first two hypotheses about gender differences in estimating self and spouse general intelligence and multiple intelligences, means and S.D. of males and females self-and-spouse estimates of general intelligence and multiple intelligences were calculated and MANOVA and ANOVA analyses were computed over both of the two sets of estimates (self and spouse) regarding general intelligence as shown in table1.

Results from table 1 showed variations in means between males and females in both self and spouse estimates of general intelligence and multiple intelligences. Also, MANOVA revealed significant differences for selfestimates only between males and females. The follow-up ANOVAs revealed that males gave significantly higher self-estimates on general $(\mathrm{F}=8.82)$ and logical intelligence $(\mathrm{F}=$ 6.68) only.

\section{Self and spouse rated intelligences' differ- ences}

A series of paired-samples $t$-test were conducted to examine differences in self and spouse estimate means differences for general and multiple intelligences for both male and female participants to test $\mathrm{H} 3$ and $\mathrm{H} 4$ hypothesis.

Table 1

Means and f-values of MANOVA and ANOVA results for self and spouse estimates

\begin{tabular}{|c|c|c|c|c|c|c|}
\hline \multirow[t]{2}{*}{ Intelligence } & \multicolumn{2}{|c|}{ Self Means \& (S.D.) } & \multirow{2}{*}{ F-value } & \multicolumn{2}{|c|}{ Spouse Means \& (S.D.) } & \multirow{2}{*}{ F-value } \\
\hline & Male & Female & & Male & Female & \\
\hline General & $\begin{array}{l}114.00 \\
(16.53)\end{array}$ & $\begin{array}{l}107.62 \\
(14.54)\end{array}$ & $8.82 * *$ & $\begin{array}{l}110.67 \\
(15.95)\end{array}$ & $\begin{array}{l}112.94 \\
(16.60)\end{array}$ & 1.03 \\
\hline Linguistic & $\begin{array}{l}117.10 \\
(17.06)\end{array}$ & $\begin{array}{l}114.67 \\
(17.52)\end{array}$ & 1.04 & $\begin{array}{l}115.28 \\
(16.22)\end{array}$ & $\begin{array}{l}116.21 \\
(18.89)\end{array}$ & 0.15 \\
\hline Logical & $\begin{array}{l}116.01 \\
(19.15)\end{array}$ & $\begin{array}{l}109.17 \\
(19.19)\end{array}$ & $6.68 * *$ & $\begin{array}{l}114.41 \\
(18.67)\end{array}$ & $\begin{array}{l}113.13 \\
(18.68)\end{array}$ & 0.25 \\
\hline Spatial & $\begin{array}{l}117.16 \\
(17.79)\end{array}$ & $\begin{array}{l}113.22 \\
(20.72)\end{array}$ & 2.19 & $\begin{array}{l}111.72 \\
(18.71)\end{array}$ & $\begin{array}{l}114.96 \\
(19.84)\end{array}$ & 1.48 \\
\hline Musical & $\begin{array}{l}105.42 \\
(21.17)\end{array}$ & $\begin{array}{l}104.30 \\
(20.75)\end{array}$ & 0.15 & $\begin{array}{l}104.24 \\
(20.14)\end{array}$ & $\begin{array}{l}104.41 \\
(19.69)\end{array}$ & 0.01 \\
\hline Kinesthetic & $\begin{array}{l}112.03 \\
(17.16)\end{array}$ & $\begin{array}{l}113.70 \\
(19.89)\end{array}$ & 0.43 & $\begin{array}{l}111.66 \\
(15.97)\end{array}$ & $\begin{array}{l}111.05 \\
(19.60)\end{array}$ & 0.06 \\
\hline Interpersonal & $\begin{array}{l}120.65 \\
(17.34)\end{array}$ & $\begin{array}{l}122.66 \\
(19.05)\end{array}$ & 0.64 & $\begin{array}{l}115.99 \\
(18.06)\end{array}$ & $\begin{array}{l}114.56 \\
(19.86)\end{array}$ & 0.30 \\
\hline Intrapersonal & $\begin{array}{l}114.28 \\
(19.57)\end{array}$ & $\begin{array}{l}116.98 \\
(20.82)\end{array}$ & 0.94 & $\begin{array}{l}112.87 \\
(17.72)\end{array}$ & $\begin{array}{l}115.55 \\
(17.96)\end{array}$ & 1.19 \\
\hline Naturalistic & $\begin{array}{l}113.48 \\
(18.98)\end{array}$ & $\begin{array}{l}110.77 \\
(19.34)\end{array}$ & 1.05 & $\begin{array}{l}111.11 \\
(18.78)\end{array}$ & $\begin{array}{l}112.37 \\
(20.36)\end{array}$ & 0.22 \\
\hline Wilks' Lambda & $0.911 *$ & & & 0.963 & & \\
\hline
\end{tabular}


Table 2

Paired samples t-test for differences in self and spouse means in general and multiple intelligences

\begin{tabular}{|c|c|c|c|c|c|c|}
\hline \multirow{3}{*}{ Intelligence } & \multirow{2}{*}{\multicolumn{2}{|c|}{$\begin{array}{c}\text { Males } \\
\text { Paired (self and Spouse) }\end{array}$}} & & \multicolumn{3}{|c|}{$\begin{array}{rr}\text { Females } \\
\end{array}$} \\
\hline & & & \multirow[b]{2}{*}{$t$} & \multicolumn{2}{|c|}{ Paired (self and spouse) } & \multirow[b]{2}{*}{$t$} \\
\hline & $\begin{array}{l}\text { Mean Differ- } \\
\text { ences }\end{array}$ & S.D. & & $\begin{array}{c}\text { Mean } \\
\text { Differences }\end{array}$ & S.D. & \\
\hline General & 3.33 & 17.71 & 1.93 & -5.32 & 16.36 & $3.34 * *$ \\
\hline Linguistic & 1.83 & 16.43 & 1.14 & -.154 & 17.13 & -0.92 \\
\hline Logical & 1.60 & 18.47 & 0.89 & -3.96 & 18.24 & $2.23^{*}$ \\
\hline Spatial & 5.44 & 22.07 & $2.52 * *$ & -1.74 & 19.18 & 0.93 \\
\hline Musical & 1.18 & 18.26 & 0.66 & -0.11 & 18.40 & 0.06 \\
\hline Kinesthetic & 0.37 & 17.73 & 0.21 & 2.66 & 18.53 & 1.47 \\
\hline Interpersonal & 4.66 & 18.09 & $2.64 * *$ & 8.10 & 16.64 & $4.99 * *$ \\
\hline Intrapersonal & 1.41 & 17.81 & 0.81 & 1.43 & 19.76 & 0.74 \\
\hline Naturalistic & 2.36 & 18.48 & 1.31 & -1.60 & 19.30 & 0.85 \\
\hline
\end{tabular}

Table 2 shows mean differences, S.D., and $t$ values for males and females self-and-spouse mean differences.

Results of table 2 shows significant differences in males mean differences between self and spouse estimates of spatial $(t=2.52)$ and interpersonal intelligences $(t=2.64)$. Also, there were statistical differences in female mean differences between self and spouse estimates in general $(t=3.34)$, logical $(t=2.23)$, and interpersonal intelligence $(t=4.99)$. These results suggest that males rate themselves higher than their spouses on spatial intelligence, and females rate their spouses higher than themselves on general and logical intelligences, while both males and females rate themselves higher than their spouses on interpersonal intelligence.

\section{Predictors of general intelligence self and spouse estimates}

To test the $\mathrm{H} 5$ hypotheses about the ability of multiple intelligences to statistically predict general self and spouse intelligence both for male and female participants, we first calculated zero-order correlations between general intelligence and the eight multiple intelligences for self and spouse estimates in the total sample and for males and females separately. These results are shown in Table 3.

Table 3

Zero-order correlations between the nine estimates for the two rating targets

\begin{tabular}{|c|c|c|c|c|c|c|c|c|c|c|c|c|c|c|c|c|c|}
\hline \multirow{2}{*}{ Sample } & \multicolumn{9}{|c|}{ Self } & \multicolumn{8}{|c|}{ Spouse } \\
\hline & & $\mathrm{G}$ & $\mathrm{L}$ & $\mathrm{Lg}$ & $\mathrm{S}$ & $\mathrm{M}$ & $\mathrm{K}$ & $\mathrm{Ie}$ & Ia & $\mathrm{G}$ & $\mathrm{L}$ & $\mathrm{Lg}$ & $\mathrm{S}$ & $\mathrm{M}$ & $\mathrm{K}$ & Ie & Ia \\
\hline \multirow{8}{*}{ Total } & $\mathrm{L}$ & .49 & & & & & & & & .49 & & & & & & & \\
\hline & $\mathrm{Lg}$ & .49 & .45 & & & & & & & .36 & .39 & & & & & & \\
\hline & $\mathrm{S}$ & .40 & .38 & .45 & & & & & & .33 & .44 & .41 & & & & & \\
\hline & M & .19 & .21 & .18 & .30 & & & & & .28 & .26 & .25 & .33 & & & & \\
\hline & $\mathrm{K}$ & .25 & .33 & .21 & .41 & .30 & & & & .32 & .37 & .36 & .52 & .30 & & & \\
\hline & $\mathrm{Ie}$ & .33 & .45 & .29 & .45 & .24 & .42 & & & .25 & .39 & .36 & .46 & .16 & .39 & & \\
\hline & Ia & .34 & .27 & .21 & .31 & .19 & .35 & .45 & & .42 & .46 & .34 & .21 & .22 & .27 & .38 & \\
\hline & $\mathrm{N}$ & .22 & .20 & .30 & .24 & .21 & .19 & .23 & .34 & .34 & .35 & .38 & .27 & .17 & .22 & .36 & .38 \\
\hline \multirow{9}{*}{ Males } & & $\mathrm{G}$ & $\mathrm{L}$ & $\mathrm{Lg}$ & $\mathrm{S}$ & $\mathrm{M}$ & $\mathrm{K}$ & Ie & Ia & $\mathrm{G}$ & $\mathrm{L}$ & $\mathrm{Lg}$ & $\mathrm{S}$ & $\mathrm{M}$ & $\mathrm{K}$ & Ie & Ia \\
\hline & $\mathrm{L}$ & .47 & & & & & & & & .48 & & & & & & & \\
\hline & $\mathrm{Lg}$ & .56 & .54 & & & & & & & .48 & .42 & & & & & & \\
\hline & $\mathrm{S}$ & .41 & .47 & .55 & & & & & & .28 & .35 & .33 & & & & & \\
\hline & M & $.16^{*}$ & $.08^{*}$ & $.16^{*}$ & .35 & & & & & .29 & .21 & .23 & .48 & & & & \\
\hline & K & .29 & .28 & .20 & .27 & .24 & & & & .31 & .44 & .31 & .47 & .44 & & & \\
\hline & $\mathrm{Ie}$ & .38 & .51 & .32 & .49 & .31 & .30 & & & .25 & .48 & .33 & .44 & .25 & .41 & & \\
\hline & Ia & .36 & .24 & $.18^{*}$ & .33 & .27 & .29 & .45 & & .43 & .42 & .39 & .22 & $.19^{*}$ & .30 & .32 & \\
\hline & $\mathrm{N}$ & .40 & .31 & .32 & .40 & .34 & $.15^{*}$ & .38 & .34 & .47 & .45 & .48 & .21 & $.12 *$ & .21 & .31 & .41 \\
\hline \multirow{9}{*}{ Females } & & $\mathrm{G}$ & $\mathrm{L}$ & $\mathrm{Lg}$ & $\mathrm{S}$ & $\mathrm{M}$ & $\mathrm{K}$ & Ie & Ia & $\mathrm{G}$ & $\mathrm{L}$ & $\mathrm{Lg}$ & $\mathrm{S}$ & M & $\mathrm{K}$ & Ie & Ia \\
\hline & $\mathrm{L}$ & .51 & & & & & & & & .50 & & & & & & & \\
\hline & $\mathrm{Lg}$ & .38 & .35 & & & & & & & .25 & .37 & & & & & & \\
\hline & $\mathrm{S}$ & .39 & .31 & .35 & & & & & & .38 & .50 & .49 & & & & & \\
\hline & M & .23 & .33 & .20 & .26 & & & & & .28 & .30 & .28 & .19 & & & & \\
\hline & $\mathrm{K}$ & .25 & .38 & .24 & .52 & .36 & & & & .33 & .33 & .41 & .57 & $.18^{*}$ & & & \\
\hline & $\mathrm{Ie}$ & .32 & .41 & .29 & .44 & $.18^{*}$ & .52 & & & .26 & .32 & .40 & .49 & $.09^{*}$ & .38 & & \\
\hline & Ia & .38 & .30 & .27 & .31 & $.13^{*}$ & .39 & .45 & & .41 & .50 & .30 & .20 & .26 & .26 & .44 & \\
\hline & $\mathrm{N}$ & $.00 *$ & $.08 *$ & .27 & $.10^{*}$ & $.09 *$ & .24 & $.10^{*}$ & .35 & .22 & .26 & .30 & .32 & .22 & .24 & .41 & .35 \\
\hline
\end{tabular}

Note: G: General, L: Linguistic, Lg: Logical, S: Spatial, M: Musical, K: Kinesthetic, Ie: Interpersonal, Ia: Intrapersonal, N:Naturalistic. $* \mathrm{P}>.05$ 
Table 4

Regression of general intelligence on the eight multiple intelligences for self and spouse

\begin{tabular}{|c|c|c|c|c|c|}
\hline \multirow{2}{*}{ Sample } & \multirow[b]{2}{*}{ Predictor } & \multicolumn{2}{|c|}{ Self } & \multicolumn{2}{|c|}{ Spouse } \\
\hline & & $\mathrm{B}$ & $\mathrm{t}$ & $\mathrm{B}$ & $\mathrm{T}$ \\
\hline \multirow{9}{*}{ Total } & Constant & 29.38 & $3.44 * * *$ & 28.11 & $3.20^{* *}$ \\
\hline & Linguistic & 0.25 & $4.06 * * *$ & 0.25 & $3.79 * * *$ \\
\hline & Logical & 0.23 & $4.13 * * *$ & 0.08 & 1.29 \\
\hline & Spatial & 0.10 & 1.71 & 0.06 & 1.00 \\
\hline & Musical & 0.02 & 0.39 & 0.08 & 1.48 \\
\hline & Kinesthetic & -0.01 & 0.23 & 0.06 & 0.95 \\
\hline & Interpersonal & -0.01 & 0.15 & -0.07 & 1.07 \\
\hline & Intrapersonal & 0.14 & $2.78 * *$ & 0.18 & $2.83 * *$ \\
\hline & Naturalistic & -0.01 & 0.12 & 0.10 & 1.72 \\
\hline \multirow{2}{*}{\multicolumn{2}{|c|}{$\begin{array}{l}F \\
\mathrm{R}_{\text {adj }}^{2}\end{array}$}} & \multicolumn{2}{|c|}{$15.35^{* * * *}$} & \multicolumn{2}{|c|}{$13.05 * * *$} \\
\hline & & \multicolumn{2}{|c|}{0.36} & \multicolumn{2}{|c|}{0.32} \\
\hline \multirow{9}{*}{ Males } & Constant & 17.49 & 1.39 & 22.33 & 1.83 \\
\hline & Linguistic & 0.13 & 1.34 & 0.23 & $2.22 *$ \\
\hline & Logical & 0.34 & $3.87 * * *$ & 0.17 & $2.07 *$ \\
\hline & Spatial & -0.03 & 0.27 & 0.01 & 0.17 \\
\hline & Musical & -0.03 & 0.48 & 0.11 & 1.45 \\
\hline & Kinesthetic & 0.10 & 1.20 & 0.03 & 0.28 \\
\hline & Interpersonal & 0.03 & 0.30 & -0.08 & 0.92 \\
\hline & Intrapersonal & 0.15 & 1.93 & 0.14 & 1.72 \\
\hline & Naturalistic & 0.15 & 1.96 & 0.18 & $2.15^{*}$ \\
\hline \multirow{2}{*}{\multicolumn{2}{|c|}{$\begin{array}{l}F \\
\mathrm{R}_{\text {adj }}^{2} \\
\end{array}$}} & \multirow{2}{*}{\multicolumn{2}{|c|}{$\begin{array}{c}9.33 * * * \\
0.39\end{array}$}} & \multicolumn{2}{|c|}{$8.09 * * *$} \\
\hline & & & & & \\
\hline \multirow{9}{*}{ Females } & Constant & 42.73 & $3.79 * * *$ & 35.19 & $2.75 * *$ \\
\hline & Linguistic & 0.29 & $3.63 * * *$ & 0.25 & $2.49 *$ \\
\hline & Logical & 0.14 & 1.96 & -0.05 & 0.52 \\
\hline & Spatial & 0.14 & $2.04 *$ & 0.13 & 1.18 \\
\hline & Musical & 0.04 & 0.58 & 0.09 & 1.20 \\
\hline & Kinesthetic & -0.08 & 1.01 & 0.09 & 1.00 \\
\hline & Interpersonal & -0.01 & 0.10 & -0.02 & 0.20 \\
\hline & Intrapersonal & 0.18 & $2.71 * *$ & 0.19 & 1.91 \\
\hline & Naturalistic & -0.12 & -1.85 & 0.01 & 0.05 \\
\hline \multirow{2}{*}{\multicolumn{2}{|c|}{$\begin{array}{l}F \\
\mathrm{R}_{\text {adj }}^{2}\end{array}$}} & \multicolumn{2}{|c|}{$7.97 * * *$} & \multicolumn{2}{|c|}{$5.88 * * *$} \\
\hline & & \multicolumn{2}{|c|}{0.35} & \multicolumn{2}{|c|}{0.27} \\
\hline
\end{tabular}

Subsequently, six multiple regression analyses were conducted with self-multiple intelligences as independent variables and self-assessed general intelligence as the dependent variable, and spouse-multiple intelligences as independent variables and spouse-assessed general intelligence as the independent variable. The analyses were conducted for the whole population; for males only and for females only (Table 4).

The results of the six regression analyses as shown in table 4 showed that all regression equations have reached the statistically significant level. It could be observed from the results shown above that:

- For the overall sample, the linguistic, logical, and intrapersonal intelligences have been significant predictors of self-rated general intelligence $(36 \%)$, while the linguistic and intrapersonal intelligences have been significant predictors (32\%) of spouse rated general intelligence.

- For male participants, the logical intelligence has been the only significant pre- dictor of self-rated general intelligence (39\%), while the linguistic, logical, and naturalistic intelligences have been significant predictors of spouse rated general intelligence (35\%).

- For female participants, the linguistic, spatial, and intrapersonal intelligences have been significant predictors of selfrated general intelligence (35\%), while the linguistic intelligence has been the only significant predictor of spouse rated general intelligence $(27 \%)$.

\section{Discussion}

This paper set out to examine sex differences in self and spouse estimates of intelligence and to explore differences between males and females self vs. spouse estimates of general and multiple intelligences and the ability of multiple intelligences in predicting general intelligence among a sample of marred Jordanian students. The current study partially replicated the results from other multiple intelligence self-estimate studies showing sex differences on general and logical intelligences. The result showed that males gave higher self-estimates 
than females on the general and the logical or mathematical intelligence. Nevertheless, there were no differences between males and females when estimating spouse's intelligences.

As has been found in studies from many other countries, males gave higher self-estimates than females on general and logical intelligence (Bailey \& Mettetal, 1977; Furnham, \& Chamorro-Premuzic, 2005; Furnham and Ward, 2001; Swami, et al., 2006). Only two studies from New Zealand (Byrd \& Stacey, 1993) and from Slovakia (Furnham, Rakow, Sarmany-Schiller, \& De Fruyt, 1999) failed to find a significant sex difference in overall selfrated IQ scores.

The previous result has been corroborated by these differences between males and females in estimating self and spouse general, logical, spatial and interpersonal intelligences. Our results showed that males gave higher selfestimates than spouse-estimates on spatial and interpersonal intelligences, while females only gave higher self-estimates than spouseestimates on interpersonal intelligence, but gave lower self-estimates than spouseestimates on general and logical intelligences.

These results together reflect two things. Firstly, that sex differences do not emerge only from overestimations of males self-estimates, but also from females underestimations of self-estimates. Kaufman (2012) interprets this finding as reflecting a lack of self-awareness or metacognition among females. In other words, sex differences in self and others-estimates of general and multiple intelligences could be explained in terms of hubris effect among males and humility effect among females. This result has been confirmed in many previous studies (Furnham \& Fukumoto, 2008; Furnham \& Ward, 2001; Furnham et al., 2005; Kaufman, 2012; Storek, 2011).

The second interesting finding regarding sex differences in self and others-estimates of general and multiple intelligences is that both males and females gave themselves higher self-estimates than spouse-estimates on interpersonal intelligence. Since interpersonal intelligence is defined as the ability to specify others' reactions, needs, emotions and purposes (Derksen, Kramer, \& Katzko, 2011; Naghavi \& Redzuan, 2011). It could be assumed that there is a "conflict" between males and females about who has more awareness of other needs and emotions. Both males and females think that they have higher interpersonal intelligence than their spouses. This result should be treated more in detail in future research, and should be related to factors influencing family and society wellbeing.

Another interesting result of the present study is related to predictors of self and spouse estimates of general intelligence from multiple intelligences. Our results showed that Jordanian students rely merely upon linguistic, logical and intrapersonal intelligences in predicting general self-estimated intelligence, and upon linguistic and intrapersonal intelligences in predicting general spouse-estimated intelligence. When it comes to sex differences in predicting general self and spouse intelligence, males only rely upon logical intelligence in predicting general self-estimated intelligence, and upon linguistic, logical and surprising naturalistic intelligence in predicting general spouse-estimated intelligence. On the other hand, females rely upon linguistic, spatial and intrapersonal intelligences in predicting general self-estimated intelligence, and only upon linguistic intelligence in predicting general spouse-estimated intelligence.

It is worth noting that linguistic and logical intelligences have been found to be significant predictors of general self-estimated intelligence in most studies carried out in different countries, and that intrapersonal intelligence has been found a significant predictor of general self-estimated intelligence only in a study carried out in Poland (Furnham, Wytykowska, \& Petrides, 2005).

This result confirmed previous research results that estimated verbal (linguistic) intelligence followed by numerical (logical) intelligence are the best significant predictors of estimated general intelligence. Although the estimated intrapersonal intelligence has not been found to be a predictor of general estimated intelligence in most studies, but some researchers maintain the importance of intrapersonal intelligence as a key human ability that has supported our survival as well as the development of a complex civilization (Shearer, 2012), therefore, it is not surprisingly to rely upon it in predicting self or others estimated general intelligence.

Findings of the present study seem to be universal where similar analyses have been done. Sex differences have been found in general, linguistic, logical, spatial and interpersonal 
intelligences, and it is often thought that some estimated intelligences such as verbal, numerical and spatial intelligence to really constitute overall general estimated intelligence.

Sex differences in self and others' estimates of intelligence have been discussed in terms of hubris-humility effects (von Stumm, Chamorro-Premuzic, \& Furnham, 2009), and selfperceptions of one's ability as predictors of achievement related behavior (Steinmayr \& Spinath, 2009). Some researchers seem concerned about examining male biases and the potentially negative consequences of hubris in self-estimated intelligence. However, it seems to be more important to study and help females who are seen to be biased in favor of modesty and lower-than actual estimations, since in this study males' estimates of spouses' general and multiple intelligences have been higher than self-estimates made by females themselves.

Finally, it is worth noting that in the current study Jordanians tended to show a hubris bias across all types of self-estimated intelligences. Although it is difficult to compare this result with others from previous studies since this the first study in Jordan and in the Arabic culture, it could be assumed that this hubris bias comes from the characteristics of the study sample which was drawn from two universities that might influence their estimations, or from the nature of the Jordanian society. More data from Jordan and other similar countries could help establish the replication of these findings and determine whether there exist broad dimensions of difference between Arabic and Western societies in perceptions and beliefs about intelligence.

In conclusion, the present study adds to the cross-cultural studies of intelligence estimation, which have now been carried out on every continent. The present results indicate that there are relatively stable cross-cultural patterns of gender differences in self-ratings, beliefs about spouse intelligence, and ideas about which of the multiple intelligences best predicts overall intelligence.

\section{References}

Bailey, R. \& Mettetal, G. (1977). Perceived intelligence in married partners. Social Behavior and Personality, 5(1), 137-141.
Beyer, S. (1999). Gender differences in accuracy of grade expectations and evaluations. Sex Roles, 41(3), 279-296.

Chmorro, T. (2016). How to accurately judge someone's intelligence. A psychologist explains why "real life is the ultimate IQ test. Retrieved on 22-6-2016 from:

http://www.fastcompany.com/3052661/k now-it-all/how-to-accurately-judgesomeone-intelligence

Derksen, J., Kramer, I., \& Katzko, M. (2002). Does a self-report measure for emotional intelligence assess something different than general intelligence? Personality and Individual Differences, 32 (1), 37-48.

Eysenck, H. (1998). Intelligence: A new look. New Brunswick, NJ: Transaction Publishers.

Eysenck, H. \& Evans, D. (1996). Know your child's IQ. London: Headstart.

Furnham, A. (2001). Self-estimates of intelligence: Culture and gender differences in self and other estimates of General (g) and Multiple Intelligences. Personality and Individual Differences, 31 (8), 1381-1405.

Furnham, A., \& Akande, A. (2004). African parents' estimates of their own and their children's multiple intelligences. Current Psycholo$g y, 22(4), 281-294$.

Furnham, A., Arteche, A., Chamorro-Premuzic, T.,Keser, A. E Swami, V. (2009). International Journal of Psychology, 44(6), 434-442.

Furnham, A., \& Chamorro-Premuzic, T. (2005). Estimating one's own and one's relatives' multiple intelligence: A study from Argentina. The Spanish Journal of Psychology, 8(1), 12-20.

Furnham, A., Fong, G., \& Martin, N. (1999). Sex and cross-cultural differences in the estimated multi-faceted intelligence quotient score for self, parents and siblings. Personality and Individual Differences, 26(6), 1025-1034.

Furnham, A., Fukumoto, S. (2008). Japanese parents' estimates of their own and their children's multiple intelligences: Cultural modesty and moderate differentiation. Japanese Psychological Research, 50 (2), 63-76.

Furnham, A., \& Gasson, L. (1998). Sex differences in parental estimates of their children's intelligence. Sex Roles, 38, 151-162. 
Furnham, A., \&Ward, C. (2001). Sex differences, test experience, and the self-estimation of multiple intelligence. New Zealand Journal of Psychology, 30 (2), 52-59.

Furnham, A., Wytykowska, A., \& Petrides, K. (2005). Estimates of multiple intelligences: A study in Poland. European Psychologist, 10(1), 51-59

Gardner, H. (1983). Frames of mind: A theory of multiple intelligences. New York: Basic Books.

Gardner, H. (1999). Intelligence reframed. New York: Basic Books.

Gardner, H. (2000). The disciplined mind: Beyond facts and standardized tests, The K12 Education That Every Child Deserves. New York: Penguin Putnam.

Gardner, H. (2006). Changing minds: The art and science of changing our own and other people's minds. Boston MA: Harvard Business School Press.

Kaufman, J. (2012). Self estimates of general, crystallized, and fluid intelligences in an ethnically diverse population. Learning and Individual Differences, 22 (1), 118-122.

Marlowe, B., \& Canestrari, A. (2006). Educational psychology in context: Readings for futureteachers. New York; Sage Publication.

Naghavi, F., \& Redzuan, M. (2011). The relationship between gender and emotional intelligence. World Applied Sciences Journal, 14 (4), 555-561.

Rammstedt, B., \& Rammsayer, T. (2002). Selfestimated intelligence: Gender differences, relationship to psychometric intelligence, and moderating effects of level of education. European Psychologist, 7, 275-284.

Shearer, B. (2012). An inter-rater reliability study of a self-assessment forth multiple intelligences. International Journal of Psychological Studies, 4 (3), 131-139.

Steinmayr, R., \& Spinath, B. (2009). What explains boys' stronger confidence in their intelligence? Sex Roles, 61, 736-749.

Storek, J. (2011). The hubris and humility effect and the domain-masculine intelligence type: explo- ration of determinants of gender differences in selfestimation of ability. Unpublished doctoral dissertation, UCL (University College London).

Swami, V., Furnham, A., \& Kannan, K. (2006).Estimating self-parentaland partner multiple intelligences: a replication in Malaysia. Journal ofSocial Psychology, 146(6), 645-55.

Von Stumm, S., Chamorro-Premuzic, T., \& Furnham, A. Decomposing self-estimates of intelligence: Structure and sex differences across 12 nations. British Journal of Psychology, 100, 429-442. 